Obere Extremität 2021 · 16:135-138 https://doi.org/10.1007/s11678-021-00644-x Received: 20 February 2021

Accepted: 6 April 2021

Published online: 5 May 2021

(c) The Author(s) 2021

\author{
Marc Schnetzke ${ }^{1,2}$ (D) Markus Loew ${ }^{1} \cdot$ Sven Lichtenberg ${ }^{1}$ \\ ${ }^{1}$ ATOS Clinic Heidelberg, German Joint Centre Heidelberg, Heidelberg, Germany \\ ${ }^{2}$ BG Trauma Center Ludwigshafen, Clinic for Trauma and Orthopaedic Surgery, University of Heidelberg, \\ Ludwigshafen on the Rhine, Germany
}

\title{
Arthroscopic osteocapsular arthroplasty for osteoarthritic elbow
}

\section{Surgical procedure}

The patient can be placed in either the prone or the lateral position for arthroscopy.

The authors prefer the prone position because of the more easily standardized portals, the freedom of movement for instrumentation, and the potential need to access the ulnar nerve. It is recommended to perform the procedure in a blood-free field.

A standardized process is helpful in encompassing and addressing all pathologies (• Fig. 1).

Prior to the start of arthroscopy, the anatomical landmarks and access sites are marked (• Fig. 2). The joint is first insufflated with about $15 \mathrm{ml}$ saline solution through the dorso-radial soft spot at the level of the soft-spot (SS) portal. The antero-lateral(AL) portal is then established and the irrigation cannula with a sharp trocar is introduced. The AL portal is furthest away from the radial nerve and therefore safest. The AL portal is created $2 \mathrm{~cm}$ proximal and $1 \mathrm{~cm}$ anterior to the lateral epicondyle. Only skin is incised to create the AL portal. Afterwards the irrigation cannula is introduced pointing toward the coronoid process. Efflux of the previously injected saline solution confirms the correct intra-articular positioning of the irrigation cannula. Once the correct intra-articular positioning is confirmed, the water feed is connected to the irrigation cannula.

\section{Posterior compartment}

The posterior compartment of the elbow is inspected first. This requires the creation of a high dorso-radial portal directly next to the triceps tendon and $1.5 \mathrm{~cm}$ proximal to the olecranon tip. This portal allows for visualization of the posterior radial and posterior ulnar groove as well as the olecranon fossa and the olecranon tip.

Loose bodies can be removed from the olecranon fossa with a grasper or shaver and adhesions released through the transtricipital portal $(3 \mathrm{~cm}$ above the olecranon tip). Following complete soft tissue debridement of the olecranon fossa, the posterior ulnar groove can be inspected. Use of the shaver should be avoided in the ulnar groove because of the proximity of, and risk of injury to, the ulnar nerve.

Osteophyte formations in the area of the olecranon fossa are now removed with the acromionizer burr until the original shape of the olecranon fossa is restored.

Osteophyte formations in the area of the olecranon tip are removed with an acromionizer burr and/or chisel. Satisfactory contouring of the olecranon is achieved once the cartilage of the trochlea is visible on $45^{\circ}$ flexion of the elbow.

\section{Dorso-radial compartment}

The posterior radial groove is then visualized and the radial head and posterior aspect of the humeral capitellum inspected cranially. There are often adhesions or plicae present here, which can be addressed with the shaver through the SS 


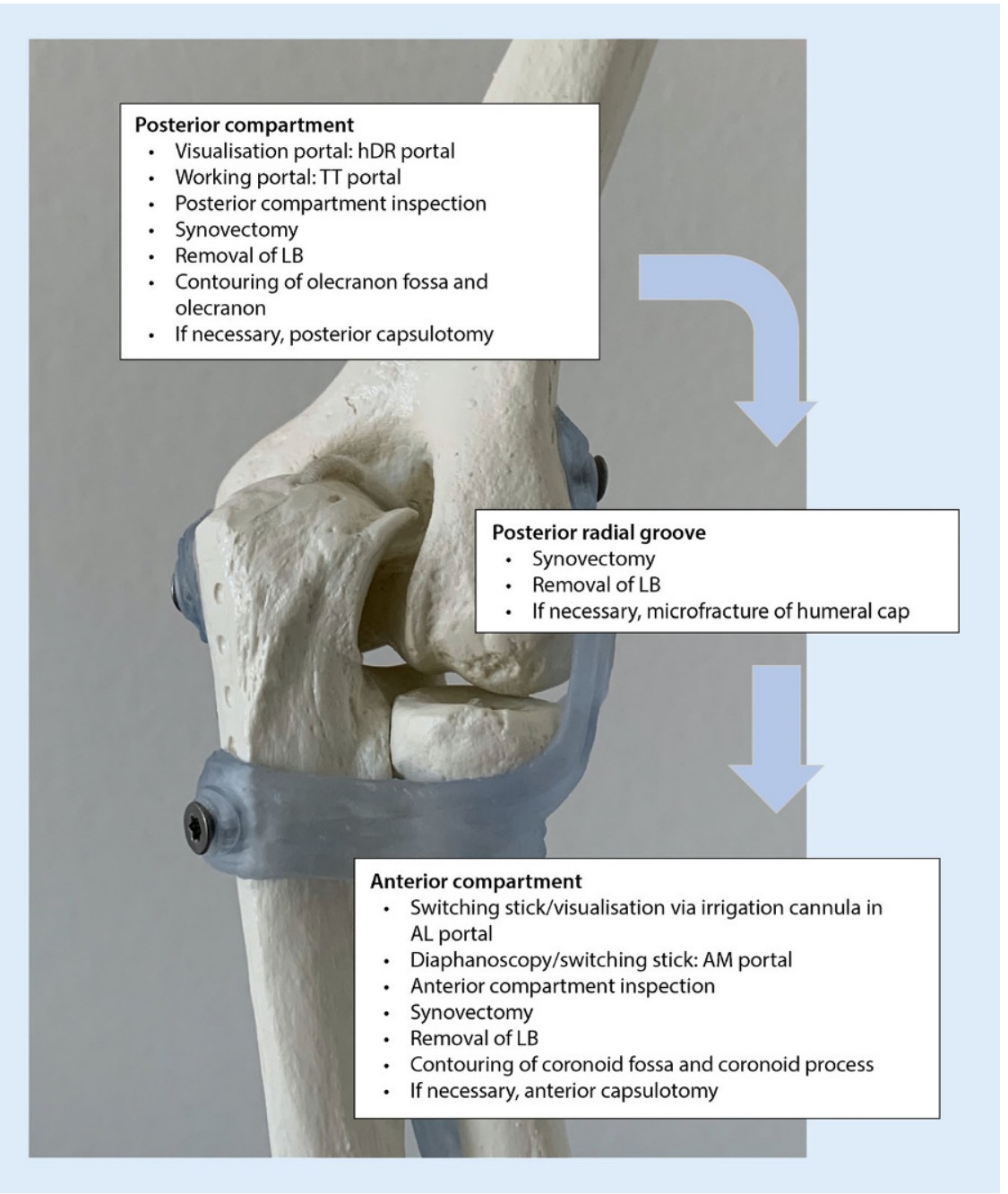

Fig. $1 \Delta$ Flow chart of standardized procedure. $h D R$ high dorso-radial, $T T$ trans-tricipital, $L B$ loose bodies, $A L$ antero-lateral, $A M$ antero-medial
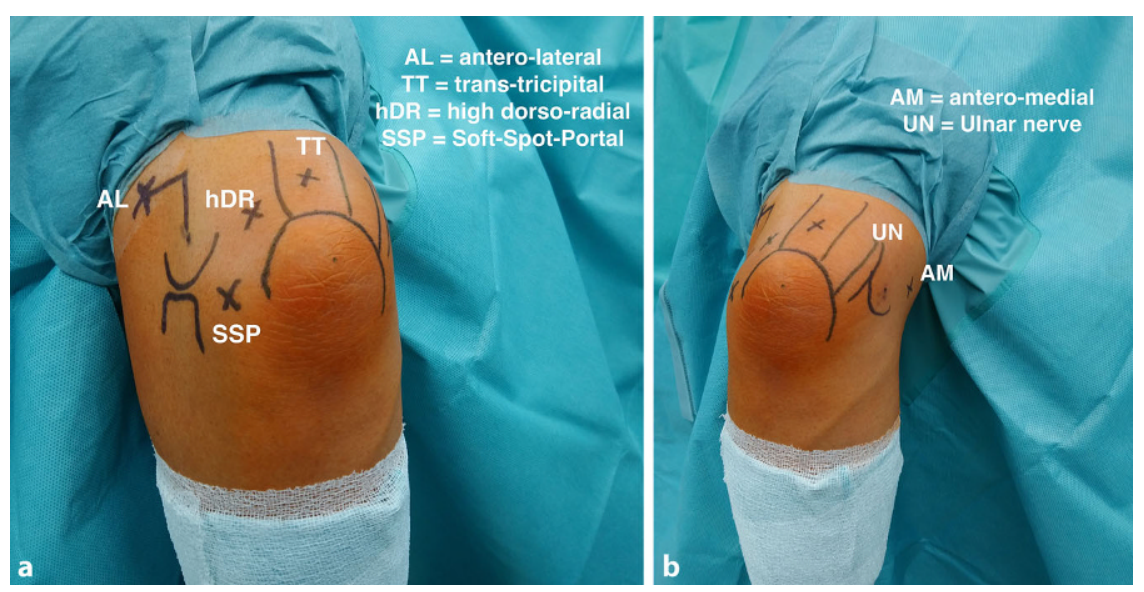

Fig. $2 \Delta$ Standard portals of elbow arthroscopy from (a) lateral and (b) medial aspect portal. In the case of locally confined cartilage damage on the humeral capitellum, microfracture can be performed from the SS portal.

\section{Anterior compartment}

In order to visualize the anterior compartment, the switching stick is introduced via the existing irrigation cannula in the $\mathrm{AL}$ portal and the camera inserted over the switching stick. In our procedure, the antero-medial (AM) portal is created by means of diaphanoscopy. The advantage of the diaphanoscopy method is that the portal can be created under visualization, so that all relevant structures can be easily reached.

The anterior compartment together with radial head, humeral capitellum, coronoid process, and coronoid fossa can be inspected and assessed through the $\mathrm{AM}$ and AL portals. Any existing synovitis is first debrided with a shaver. As in the posterior compartment, fixed bodies adhering to the capsule are freed from their adhesions and reduced in size before being retrieved with a grasper. In the case of very large loose bodies, it is usually necessary to extend the incision beforehand. After complete synovectomy, osteophytes in the area of the coronoid tip are resected. This is performed alternately with an acromionizer burr and a shaver. Because of the difficult angulations, we also used curved chisels in our procedure. Osteophytes in the coronoid fossa are removed up to the cartilage margin of the trochlea. Due to the anatomically very tight joint space, it can be helpful to keep the joint open via an accessory AL portal with the help of an exchangeable rod. This effectively prevents collapse of the joint. As with the standard portals, care must be taken when creating the additional AL portal to ensure proximity to the nerves (radial nerve, antebrachial cutaneous nerve).

In patients with a preoperative extension deficit, it is recommended to perform an anterior capsulotomy or capsulectomy. Anterior capsulotomy is technically demanding because of the proximity of the neurovascular structures, the median nerve, and the deep branch of the radial nerve. The capsule must be 
resected until the muscle fibers of the brachial muscle become visible.

\section{Wound closure}

Prior to wound closure, the elbow joint is ranged to check the mobility obtained. The incisions are closed with skin sutures and an elastic bandage is applied to the elbow. Immobilization is not necessary. The authors recommend postoperative ossification prophylaxis with a nonsteroidal anti-inflammatory drug after aOCA [3]. If there is a contraindication, radiotherapy should be performed preoperatively.

\section{Discussion}

The aOCA represents a technically sophisticated and minimally invasive method for the treatment of arthrosis of the elbow joint. According to our own experience and the literature, aOCA is indicated for grade I-II arthrosis according to Morrey. If the degree of arthrosis is higher, grade III-IV, with an extension deficit of more than $30^{\circ}$ and a flexion of less than $90^{\circ}$, open arthrolysis or partial/ total joint replacement is more likely to be indicated [2].

The literature results for arthroscopic debridement in the osteoarthritic elbow are confined mainly to limited case series. The largest patient cohort to date $(n=87)$ was followed up in a French multicenter study published in 2019 [1]. The authors report that the patients exhibited a significant improvement in pain $(6.4 \pm 2.1$ vs. $1.7 \pm 1.8)$, functionality $(113.6 \pm 25.4$ vs. $178.7 \pm 20.2)$, and both extension/flexion $\left(93^{\circ} \pm 21\right.$ vs. $\left.124^{\circ} \pm 14\right)$ and pronation/ supination $\left(148^{\circ} \pm 26\right.$ vs. $\left.163^{\circ} \pm 21\right)$.

In a review, Sochaki et al. included nine studies and analyzed the results of arthroscopic treatment in primary elbow osteoarthritis [5]. In total, 213 patients were included in the evaluation with a follow-up period of $42 \pm 16$ months. Range of motion improved significantly for extension (preoperative: $23^{\circ}$ vs. postoperative: $11^{\circ}$ deficit) and flexion $\left(116^{\circ}\right.$ vs. $\left.129^{\circ}\right)$. The functional outcome, measured by the Mayo Elbow Performance Score, also showed a significant improve- ment from the preoperative to postoperative period (61 vs. 85 points).

\section{Practical conclusion}

- Arthroscopic osteocapsular arthroplasty for osteoarthritis of the elbow is a technically demanding intervention.

- If the indication is established correctly and the procedure performed in the correct manner, a significant improvement in range of motion and functionality of the elbow can be achieved with this intervention.

\section{Corresponding address}

\section{Marc Schnetzke, MD}

ATOS Clinic Heidelberg, German Joint Centre Heidelberg

Bismarckstraße 9-15, 69115 Heidelberg,

Germany

marc.schnetzke@atos.de

Funding. Open Access funding enabled and organized by Projekt DEAL.

\section{Declarations}

Conflict of interest. M. Loew received royalties from Wright/Tornier Inc., which is not related to the subject of this work. S. Lichtenberg is a paid consultant for Arthrex and Exactech and has received royalties from Arthrex, which is not related to the subject of this work. M. Schnetzke declares that he has no competing interests.

For this article no studies with human participants or animals were performed by any of the authors. All studies performed were in accordance with the ethical standards indicated in each case.

Open Access. This article is licensed under a Creative Commons Attribution 4.0 International License, which permits use, sharing, adaptation, distribution and reproduction in any medium or format, as long as you give appropriate credit to the original author(s) and the source, provide a link to the Creative Commons licence, and indicate if changes were made. The images or other third party material in this article are included in the article's Creative Commons licence, unless indicated otherwise in a credit line to the material. If material is not included in the article's Creative Commons licence and your intended use is not permitted by statutory regulation or exceeds the permitted use, you will need to obtain permission directly from the copyright holder. To view a copy of this licence, visit http://creativecommons.org/licenses/by/4.0/.

\section{References}

1. Carlier $Y$, Lenoir $H$, Rouleau DM, Mansat $P$, Vidil $A$, Ferrand M, Bleton R, Herrisson O, Salabi V, DuparcF, Kelberine F, Desmoineaux P (2019) Arthroscopic debridement for osteoarthritis of the elbow: results and analysis of predictive factors. Orthop Traumatol Surg Res 105(8s):S221-s227. https:// doi.org/10.1016/j.otsr.2019.09.002

2. Morrey BF (2000) The elbow and its disorders, 3rdedn. Saunders, Philadelphia

3. Nelson GN, Wu T, Galatz LM, Yamaguchi K, Keener JD (2014) Elbow arthroscopy: early complications and associated risk factors. J Shoulder Elbow Surg 23(2):273-278. https://doi.org/10. 1016/j.jse.2013.09.026

4. O'Driscoll SW, Blonna D (2014) Osteocapsular arthroplasty of the elbow: surgical technique. JBJS Essent Surg Tech 3(3):e15. https://doi.org/10 2106/jbjs.St.M.00002

5. Sochacki KR, Jack RA 2nd, Hirase T, McCulloch PC, Lintner DM, Liberman SR, Harris JD (2017) Arthroscopic debridement for primary degenerative osteoarthritis of the elbow leads to significant improvement in range of motion and clinical outcomes: a systematic review. Arthroscopy 33(12):2255-2262. https://doi.org/10.1016/j. arthro.2017.08.247

6. Stanley D (1994) Prevalence and etiology of symptomatic elbow osteoarthritis. J Shoulder Elbow Surg 3(6):386-389. https://doi.org/10. 1016/s1058-2746(09)80024-4 
Hier steht eine Anzeige.

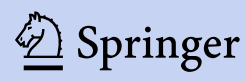

